\title{
Analysis of Literature Statistics on Chinese College Students' English Learning Motivation
}

\author{
Shuyan $\mathrm{Xu}^{1, \mathrm{a}}$, Xianhua Yang ${ }^{2, \mathrm{~b}}$ \\ ${ }^{1}$ College of Language and Cultural Communication of Shangluo University, Shangluo, Shaanxi, \\ China \\ ${ }^{2}$ College of Humanities \& Social Sciences of Shangluo University, Shangluo, Shaanxi, China \\ a lorraine2004@163.com, b emery10818@sina.com
}

Keywords: Chinese college students; English learning motivation; Core journals of foreign languages; Literature statistics.

\begin{abstract}
Using the method of literature statistics, 195 documents about college students' English learning motivation are analyzed. 10 papers published in core journals of foreign languages are reviewed in multi-perspectives from several aspects: research contents, authors, document originals, published time, research types, research methods, participants, writing forms and funding supports. On this basis, limitations of research on Chinese college students' English learning motivation are explored, and the further research on this field is prospected.
\end{abstract}

\section{Introduction}

With the increasing problems about college students' learning motivation and the growing needs to enhance the quality of language learning, educators, under modern information technology, have explored their language learning, especially English learning motivation for many years, in the aspects of its type, characteristics, stimulating and cultivation of strategies. They aim to improve college students' language learning proficiency as well as quality, and cultivate learners to acquire a higher language competence in listening, speaking, reading and writing.

In China, literatures on college students' English learning motivation have increased annually since the year 2000. And this kind of motivation has become one of heated topics which have been discussed by many researchers using various methods. To our delight, researchers have made great achievements. With the purpose to better promote relevant research at home, and provide reference for future study, this paper, based on the biblio-metrics method, searches for 195 documents on college students' learning motivation, which were published from July 1, 2000 to Dec. 31, 2008. In order to know these years' studying condition in this field, and provide scientific basis for related research and practice in future, it mainly makes detailed analysis and review of 10 articles in core journals of foreign languages.

But the studies has been discussed do not have solid foundation for further study. With the purpose to better promote relevant research at home, and provide reference for future study, this paper, based on the biblio-metrics method, searches 195 documents on college students' learning motivation, which were published from July 1, 2000 to Dec. 31, 2008. It mainly makes detailed analysis and review of 10 articles on core journals of foreign languages, in order to get to know these years' studying condition in this field, and provide scientific basis for related research and practice in future. The paper aims to study from three aspects: First, general analysis on English learning motivation; secondly, data analysis on college students' English learning motivation in core journals of foreign language.

\section{Measuring Auto Body Panels}

\subsection{Research Contents and Methods}

Through CNKI, the author accurately retrieves fourth times: "college and English learning motivation”, “college and foreign learning motivation”, “college students and English learning 
motivation”, “college students and foreign learning motivation”. In total, there are 263 documents on college students' learning motivation, which were published from July 1, 2000 to Dec. 31, 2008, deleting 68 documents which are the same. After that, leaving 195 documents, among of them, 171 documents on college (students') English learning motivation, 24 documents on college (students') foreign learning motivation.

\subsection{Literature Selecting}

It is generally believed that core journals of foreign language are the most authoritative document. The papers that are published on it represent prospect of fields of foreign subjects. After retrieving, in all, 10 documents fitting studies.

\section{Results and Analysis}

\subsection{General Analysis on College Students' English Learning Motivation}

Results of the study show that the 195 documents about college students' English learning motivation are mainly collected in journals, master and doctoral dissertations, and meeting abstracts. Overall, 143 journal papers are dominated, occupying 73.34\% of the total number of literature. Among them, 133 are included in core journals of non-foreign language, with the highest proportion of $68.21 \%$. While 10 in core journals of foreign language is only accounting for $5.13 \%$ of the total number of literature. And 50 master theses, 1 doctoral dissertation and 1 meeting abstract have their relative proportions being $25.64 \%, 0.51 \%$, and $0.51 \%$ respectively.

\subsection{Data Analysis on College Students' English Learning Motivation in Core Journals of Foreign Language}

The 10 papers concerning about college students' English learning motivation published in core journals of foreign language are analyzed in respect of research contents, authors, document originals, published times, research types, research methods, participants, writing forms and funding supports.

\subsubsection{Research contents}

For research contents, these papers mainly discuss types and developing characteristics of English learning motivation, and its relations and changes with correlated factors. Furthermore, the types and characteristics as well as the tendency of non-English majors' English learning motivation and its respective relations with autonomous English learning ability and academic performance are observed and studied. In addition, follow-up survey on intensity of English majors' motivation and change of self-identity are made, and the main causes for college students' passive state in English learning are examined around the issue of transformation of the English learning motivation

\subsubsection{Authors}

For authors, researchers from Beijing University are the most, writing 6 of them. And Hainan University, Hanshan Normal University, Sichuan Normal University, and Northwestern Polytechnic University write 1 paper respectively.

\subsubsection{Document original}

For document originals, 3 are published on Teaching English in China, 2 in Foreign Language Teaching Abroad, and 5 separately in Journal of Tianjin Foreign Studies University, Foreign Languages in China, Foreign Language and Literature Studies, Foreign Languages Research, and Modern Foreign Languages.

\subsubsection{Published times and types}

For published time, 3 were published respectively in 2000, 2002, and 2006. 2 respectively is in 2003 and 2005; 3 is in 2008. Therefore, overall papers of high level on college students' English learning motivation are increasing year by year. For research types, among them, 9 are empirical research, 1 is theoretical comment and review.

\subsubsection{Research methods}

For research methods, most papers adopt questionnaire investigation to carry on quantitative study, combination discussion between quantitative and quality study, follow-up study, and relevant study of some related questions. With regard to measurement tool, it is represented by college students' 
English learning motivation questionnaire from Gao Yihong. Besides, both Shi Yongzhen(2000) and Zou Huimin(2005) also develop questionnaires for measuring students' English learning motivation.

\subsubsection{Participants}

For participants, in terms of education background, these papers chiefly aims at undergraduate students. Referring to discipline, non-English majors are most, and English majors are least. In view of grade, by taking into account the characteristics of students' English learning motivation in different grades, discussions mainly focus on the motivation of sophomores.

\subsubsection{Writing forms}

For writing forms, the papers discussed here are mainly in Chinese. Only 3 are written in English, which is published on Teaching English in China.

\subsubsection{Funding supports}

For funding supports, few papers are supported by the National Social Science Foundation with an exception of only one article by GaoYihong (2008).

\subsubsection{Research cites}

For cites, the cited rate of the paper from Shi Yongzhen (2000) is 54, from Gao Yihong (2002) is 31, two papers from Gao Yihong and others (2002) is 198 and 103 respectively, and from Zou Huimin and others (2005) is 5. However, four articles published since 2006, are not cited.

\section{Research Limitations and Prospect of College Students' English Learning Motivation}

\subsection{General Level of Documents Should Be Further Improved}

Among the 195 documents, only 10 are published in core journals of foreign language. This suggests that higher quality academic papers are relatively fewer. From published time, we can see that although academic papers are increasing annually, just a few of them are higher quality ones. Researcher should improve their thesis quality; which helps promote a further and deeper study in the field of English learning motivation. In addition, meeting abstract and the research paper getting fund support are rare. To participate in international and domestic related field seminar or increase fund support is one of the important ways to improve research ability and paper quality. Therefore, in future study it is quite necessary to place more importance to session and exchange, and increase fund support, especially to major projects of the ministry of education.

\subsection{Influencing Mechanism between Variables Need to Be Further Studied}

In the previous studies, researchers mainly discuss types and developing characteristics of English learning motivation, and its relations and changes with the correlated factors, such as autonomous learning ability, self-identification, and academic performance. From the review of study in recent 10 years, we find that it lacks some proper expansions of research contents. For instance, students' learning motivation, and emotion status (such as anxiety, fear, pride) are closely related to their academic performance. However, the study of specific influencing mechanism between variables almost remains a gap. Based on relevant social constructivism, the exploration of the internal mechanism between English learning motivation, coping ways and academic performance, is beneficial to the deepening of language learning theory and the practice of English teaching. Although most of existing studies carry on quantitative study, combination discussion between quantitative and quality study, follow-up study, relevant study of some related questions; it is lack of dynamic results which can get from the intervention study on college students' English learning motivation. In other words, it is loss of the support from more precise experiment data derived from more complicated experiment designs.

\subsection{Local Research Needs to Cooperate}

For authors, researchers from Beijing University are most, and they make study in teams. However, other universities, especially local colleges do very little high quality research on related problems of English learning motivation. In spite of the relatively poor conditions in geographical location, school environment, student levels and teaching resources, more attention should be put into the type, characteristics and stimulating strategy of local college students' English learning motivation, so as to 
examine the universality and specificity of college students' English learning motivation. In terms of measuring tool, it is represented by college students' English learning motivation questionnaire developed by Gao Yihong. Based on its fine reliability and validity, it is expected that lots of localized, cross district even cross-culture studies are made. Thus, local universities can cooperate and develop local research, in order to enhance the research validity of college students' English learning motivation, make contribution to English learning in local universities, and improve the international influence of domestic study by using various writing forms.

\subsection{Theory Research Needs to Be Innovative Application}

Since the 1980s, the domestic relevant empirical studies on English learning motivation have increased, which, to some extent, have changed previous train of thoughts oriented by qualitative research, but it doesn't mean that theoretical research is no longer important. Recent 10 years' study results show empirical research is much more than theoretical research. To certain extent, this heads for another extreme, to be specific, putting too much attention to natural science empirical research results whereas ignoring the necessity of social science theoretical research results. Psychologist Kurt Lewin once said: "there is nothing more convincing than a good theory" Thus, future research should innovate in theory based on the existing theoretical study, properly add some papers of theoretical review, and make prompt integration and analysis of the study results, based on the precision improvement of empirical research, which will leave a closer connection between empirical and theoretical research.

\subsection{Research Object Need to Be Expanded}

Select students, whose English learning ability or English learning anxiety vary from high to low state, as study object, explore the interaction between English learning ability or anxiety and learning motivation. The future research needs to make the cross-sectional and longitudinal combining study, choose subjects of different grade, major, and discipline, and use various sampling methods such as random or stratified sampling, and many statistical analyses, in order to raise utilization and thrift ratio of study object, and improve the performance and external validity of research results. What's more, the future research can also try selecting subjects cross district or culture to do comparative study on second language learning motivation.

\section{Acknowledgment}

This research is the Scientific Research Program Funded by Shangluo University (Program No.14SKY-FWDF010) and also the Teaching Reform Program Funded by Shangluo University(Program No.15jyjx112).

\section{References}

[1]. Yihong Gao, Lu Liu and Limei Xiu, “Longitudinal Study on English Learning Motivation: Based on Sampling of English Majors in a Comprehensive University,” Journal of Tianjin Foreign Studies University, vol.11, pp.67-73, 2008.

[2]. Honggang Liu, "ELF Motivations and Autonomy in English Learning: An Investigation of Chinese Non-English Major Undergraduates,” Teaching English in China, vol.10, pp.82-97, 2008.

[3]. Lu Liu and Yihong Gao, "English Learning Motivation and Self-identity Changes: A Longitudinal Study on Second Year English Majors in a Comprehensive University,” Foreign Languages in China, vol. 2, pp. 40-45, 2008.

[4]. Tianfa Wang, “Less Successful Students’ Motivation and Their Test Performances,” Teaching English in China, vol.12, pp.50-55, 2006. 
[5]. Huimin Zou and Zhiyu Cai, "Motivation Inclination for Foreign Language Learning: Empirical Study on Chinese College Students,” Foreign Language and Literature Studies, vol.6, pp.118-123, 2005.

[6]. Xueping Gong, "Motivation Transformation in English Learning: A Study on Curriculum Requirements, ” Teaching English in China, vol.2, pp.108-112, 2005.

[7]. Yihong Gao, Ying Cheng and Yuan Zhao, "Types of English Learning Motivation and Intense of Motivation: Quantitative study Based on Four Year Students,” Foreign Languages Research, vol.2, pp.60-64, 2003.

[8]. Yihong Gao,Yuan Zhao and Ying Cheng, "Motivation Types of Chinese College Undergraduates,” Modern Foreign Languages, vol.1, pp.29-38, 2003.

[9]. Yihong Gao, Yuan Zhao and Ying Cheng, “ Four Year College Students' Types of English Learning Motivation and Self- identity Changes,” Teaching English in China, vol.11, pp.18-24, 2002.

[10]. Yongzhen Shi, “Survey on College Students’ English Learning Motivation,” Teaching English in China, vol.4, pp.8-11, 2000. 